\title{
Advantages and applications of CAR-expressing natural killer cells
}

\author{
Wolfgang Glienke ${ }^{1}{ }^{*}$, Ruth Esser ${ }^{1}$, Christoph Priesner ${ }^{1}$, Julia D. Suerth ${ }^{2}$, Axel Schambach ${ }^{2}$, \\ Winfried S. Wels ${ }^{3}$, Manuel Grez ${ }^{3}$, Stephan Kloess' ${ }^{1}$, Lubomir Arseniev' and Ulrike Koehl' ${ }^{1}$ * \\ 1 Institute of Cellular Therapeutics Integrated Research and Treatment Center Transplantation, Hannover Medical School, Hannover, Germany \\ 2 Institute of Experimental Hematology, Hannover Medical School, Hannover, Germany \\ ${ }^{3}$ Georg-Speyer-Haus, Institute for Tumor Biology and Experimental Therapy, Frankfurt am Main, Germany
}

\section{Edited by:}

Eric Robinet, Universitaire de

Strasbourg, France

\section{Reviewed by:}

Nadezhda A. German, Texas Tech University Health Science Center, USA

Aurore Saudemont, Anthony Nolan/University College London, UK Masaki Yasukawa, Ehime University Graduate School of Medicine, Japan

\section{*Correspondence:}

Wolfgang Glienke and Ulrike Koehl Institute of Cellular Therapeutics Integrated Research and Treatment Center Transplantation, Hannover Medical School, Feodor-Lynen-Street 21, 30625 Hannover, Germany e-mail: glienke.wolfgang@mhhannover.de:

koehl.ulrike@mh-hannover.de
In contrast to donor T cells, natural killer (NK) cells are known to mediate anti-cancer effects without the risk of inducing graft-versus-host disease (GvHD). In order to improve cytotoxicity against resistant cancer cells, auspicious efforts have been made with chimeric antigen receptor (CAR) expressing T- and NK cells. These CAR-modified cells express antigen receptors against tumor-associated surface antigens, thus redirecting the effector cells and enhancing tumor-specific immunosurveillance. However, many cancer antigens are also expressed on healthy tissues, potentially leading to off tumor/on target toxicity by CAR-engineered cells. In order to control such potentially severe side effects, the insertion of suicide genes into CAR-modified effectors can provide a means for efficient depletion of these cells. While CAR-expressing T cells have entered successfully clinical trials, experience with CAR-engineered NK cells is mainly restricted to pre-clinical investigations and predominantly to NK cell lines. In this review we summarize the data on CAR expressing NK cells focusing on the possible advantage using these short-lived effector cells and discuss the necessity of suicide switches. Furthermore, we address the compliance of such modified NK cells with regulatory requirements as a new field in cellular immunotherapy.

Keywords: CAR, suicide genes, NK cells, T cells

\section{INTRODUCTION}

Cell-based therapies are becoming more and more important for the treatment of disease progression in cancer, severe infection, or GvHD occurring after stem cell (SCT) or organ transplantation. Beside hematopoietic stem cells, dendritic cells, mesenchymal stromal cells, unselected $\mathrm{T}$ lymphocytes, and antigen-specific or regulatory $\mathrm{T}$ cells, alloreactive NK cells are currently getting into the focus of interest as suitable and powerful effector cells for cellular therapy of cancer (Velardi, 2012). NK cells are defined as CD56+ and CD3- cells and are subdivided into cytotoxic $\mathrm{CD} 56^{\mathrm{dim}} \mathrm{CD} 16^{+}$and immunoregulatory $\mathrm{CD} 56^{\text {bright }} \mathrm{CD} 16^{-}$cells. NK cells are of great clinical interest because they contribute to the graft-versus-leukemia/tumor $(\mathrm{GvL} / \mathrm{GvT})$ effect but are not responsible for the GvHD. However, the strong cytotoxicity of NK cells can be hampered by various tumor immune escape mechanism (Raffaghello et al., 2004; Holdenrieder et al., 2007; Kloess et al., 2010). In order to improve cytotoxic activity, effector cells can be efficiently and specifically redirected by recombinant chimeric antigen receptors (CARs), which consist of a single-chain variable fragment (scFv; ectodomain) linked to intracellular signaling domains (endodomain). The scFv binds to a defined target antigen on, i.e., cancer cells and triggers effector cell activation upon target engagement.

Extensive pre-clinical studies over the last decades have led to successful clinical phase I/II studies with CAR expressing T cells in hematological malignancies, including lymphoma, chronic lymphocytic leukemia (CLL), and acute lymphoblastic leukemia (ALL;
Brentjens et al., 2010; Porter et al., 2011; Kochenderfer et al., 2012, 2013; Grupp et al., 2013; Maude et al., 2014). Especially CD19 CAR T cells have induced long-term remissions in patients with B cell malignancies (Grupp et al., 2013). Currently, a broad range of different cancer target antigens is under clinical investigation in several clinical CAR T cell trials such as CD20, CD30, CD138, c-Met, EGFRvIII, FAB, GD2, HER2, WT1, PSMA, NY-ESO1, and others as reviewed in Corrigan-Curay et al. (2014) and Maus et al. (2014) and even more target antigens are under pre-clinical development (Kenderian et al., 2014; Leuci et al., 2014). In contrast to numerous pre-clinical and clinical trials in the context of CARmodified T cells, little is known on CAR-engineered NK cells. Therefore the present review focuses on engineered NK cells from pre-clinic to clinic and addresses the question of the necessity of suicide switches to improve the safety of CAR-expressing NK cells.

\section{NK CELL SOURCES}

Natural killer cells can be generated from different sources such as peripheral blood (PB), unstimulated leukapheresis products (PBSC), umbilical cord blood (UCB), bone marrow (BM), human embryonic stem cells (hESCs) or induced pluripotent stem cells (iPCSs; Woll et al., 2009; Chouaib et al., 2014). While the generation of NK cells from hESCs or iPCS has been largely experimental to date, the ex vivo expansion and NK differentiation of UCB-derived CD34 ${ }^{+}$cells has been successfully translated to the clinics (Spanholtz et al., 2011). An ongoing phase I clinical trial uses NK cells produced from $\mathrm{CD} 34^{+}$hematopoietic precursors to 
treat acute myeloid leukemia (AML) in elderly patients (CCMO nr. NL31699 and Dutch Trial Register nr. 2818). In the last decade effective methods for clinical grade purification and expansion of donor NK cells from PB and PBSC have been established successfully in order to obtain large numbers of NK cells (Iyengar et al., 2003; Koehl et al., 2005, 2013; Miller et al., 2005; Sutlu et al., 2010; Leung, 2011; Leung et al., 2014). In this respect, feasibility and safety of NK cell therapies has been shown in several phase I/II trials performing both the adoptive transfer of donor NK cells without transplantation (Miller et al., 2005) or donor-derived allogeneic NK cells post-SCT (Koehl et al., 2004; Stern et al., 2013; Leung etal., 2014). Depending on the source and the protocol, more immature, such as polyfunctional CD56 ${ }^{\mathrm{dim}} \mathrm{KIR}^{+} \mathrm{CD} 62 \mathrm{~L}^{+}$

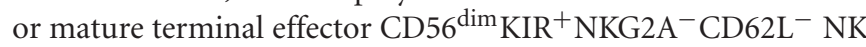
cells are available for the use in clinical studies (Luetke-Eversloh et al., 2013).

Next to primary human NK cells, cell lines can also be useful for allogeneic NK cell therapy. Several human NK cell lines have been established, i.e., NK-92, HANK-1, KHYG-1, NK-YS, NKG, YT, YTS, NKL reviewed in Kornbluth et al. (1985) and NK3.3 Cheng et al. (2012). Among them, the NK-92, KHYG-1, NKL, and NKG cell lines exert well-documented antitumor activities (Yagita et al., 2000). Beyond these pre-clinical investigations, NK-92 has also entered clinical trials successfully (Tonn et al., 2013).

\section{CAR EXPRESSING NK CELLS}

Ex vivo expanded primary human NK cells produce a different spectrum of cytokines compared to T cells including $\gamma$-Interferon, IL-3 and the granulocyte macrophage colony stimulating factor (GM-CSF; Huenecke et al., 2010; Klingemann, 2014). CARmodified NK cells can represent a complementary therapeutic option to CAR-expressing $\mathrm{T}$ cells. To date, pre-clinical data have been reported for CAR-modified primary human NK cells redirected against CD19, CD20, CD244, and HER2 as well as CAR-expressing NK-92 cells targeting a broader range of cancer antigens (Table 1).

Several of the pre-clinical studies with CAR-expressing NK cells focus on anti-CD19 and anti-CD20 CARs targeting B cell malignancies (Imai et al., 2005; Muller et al., 2008; Boissel et al., 2009, 2013; Li et al., 2010; Shimasaki et al., 2012). Other preclinical studies have used the ganglioside GD2 as an antigen to target neuroblastoma (Altvater et al., 2009; Esser et al., 2012). An additional field for anti-GD2 CAR therapy could be opened by the finding that breast cancer stem cells are GD2 positive as well (Battula et al., 2012). HER2 may represent another attractive target for CAR-based immunotherapies if current safety concerns can be adequately addressed (Morgan et al., 2010). HER2 is overexpressed in $30-80 \%$ of human breast, ovarian, pancreatic, colon, gastric, lung, prostate carcinomas as well as melanomas, and correlates with a more aggressive disease progression (Uherek et al., 2002; Kruschinski et al., 2008; Schonfeld et al., 2014). A CAR targeting the pan-cancer antigen "Epithelial cell adhesion molecule" (EpCam) was successfully tested in NK-92 cells (Sahm et al., 2012). Further, CARs, that have been pre-clinically evaluated in the NK cell context, target GPA7 (Zhang et al., 2013), CD138 (Jiang et al., 2014), and CS1 (Chu et al., 2014a), which are present on multiple myeloma. Retroviral transduction of an NKG2D-DAP10-CD3 $\zeta$
CAR that utilizes the extracellular domain of NKG2D for recognition of natural NKG2D ligands on the tumor cell surface, markedly increased NKG2D surface expression in NK cells, which became more cytotoxic against leukemia and solid tumor cell lines (Chang et al., 2013).

Importantly, also non-cancer targets can be eliminated by redirected NK cells. For example, an anti-EBNA3C CAR was used for the NK cell-mediated destruction of EBV positive T cells (Tassev et al., 2012) and an anti-CD4 CAR for the elimination of HIVinfected cells (Ni et al., 2014), overall demonstrating the huge potential of CAR-modified NK cells. To date, investigations about CAR expressing NK cells report on the overall NK cells and do not differ between specific NK cells subpopulations and maturation status of the NK cells. Mature donor NK cells purified from PB and activated with cytokines have a limited lifespan of a few days up to a few weeks (Brehm et al., 2011, 2014). Hence, allogeneic CAR-engineered NK cells are expected to be rejected or exhausted after destroying the cancer cells. In contrast, more immature NK cells derived from cord blood (Spanholtz et al., 2011) or from iPSC (Ni et al., 2014) have a longer lifespan which may allow extended antitumor activity, but also increases the risk of malignant transformation and other adverse effects, thus requiring improved safety strategies.

\section{VECTORS FOR TRANSDUCTION OF NK CELLS AND TRANSDUCTION EFFICACY}

Stable gene transfer is required to enable sustained CAR expression in expanding and persisting effector cells (Sadelain et al., 2013). CAR endodomains are responsible for transmitting the activating signal within the lymphocytes. In first generation CARs, usually the cytoplasmic $\mathrm{CD} 3 \zeta$ domain of the TCR complex was used as an endodomain (Irving et al., 1993). The potency of CARs can be increased by addition of one (second generation CAR) or more co-stimulatory domains (third generation CAR), derived from, e.g., CD28, OX-40, or 4-1BB. To increase the specificity of effector cells, also two separate chimeric proteins can be co-expressed, one representing a low-affinity activating $\mathrm{CD} 3 \zeta$ receptor specific for a first tumor-associated antigen, the other receptor harboring a costimulatory domain fused to an antigen-binding domain targeting a second antigen. Only when both components are triggered, the effector cells will sufficiently be activated to achieve cytolytic activity (Park et al., 2011; Sadelain et al., 2013; Corrigan-Curay et al., 2014). In general, CAR affinity and functionality is determined by the interplay between the antigen-binding scFv (single chain variable fragment) antibody, hinge region, transmembrane region, and endodomain. Thus, CARs should be experimentally optimized for each target antigen and application.

Retro- or lentivirus-based vectors have mostly been used for CAR-engineered NK cells with various transduction efficacies. Imai etal. (2005) reported retrovirus-based transduction of a CD19-specific CAR construct with an efficacy of $43-93 \%$ in expanded primary NK cells. Another method of CAR transfection into NK cells is electroporation of plasmid DNA or mRNA ( $\mathrm{Li}$ et al., 2010). In one study a comparison of mRNA transfection and lentivirus-based transduction of CD19 and CD20 CAR constructs showed a lower efficacy $(<10 \%)$ in the electroporation approach in $\mathrm{PB}$ and cord blood NK cells, in comparison to a transduction 
Table 1 | Pre-clinical trials using CAR-engineered primary human NK cells and Pre-clinical investigations of CAR-expressing NK-92 cells.

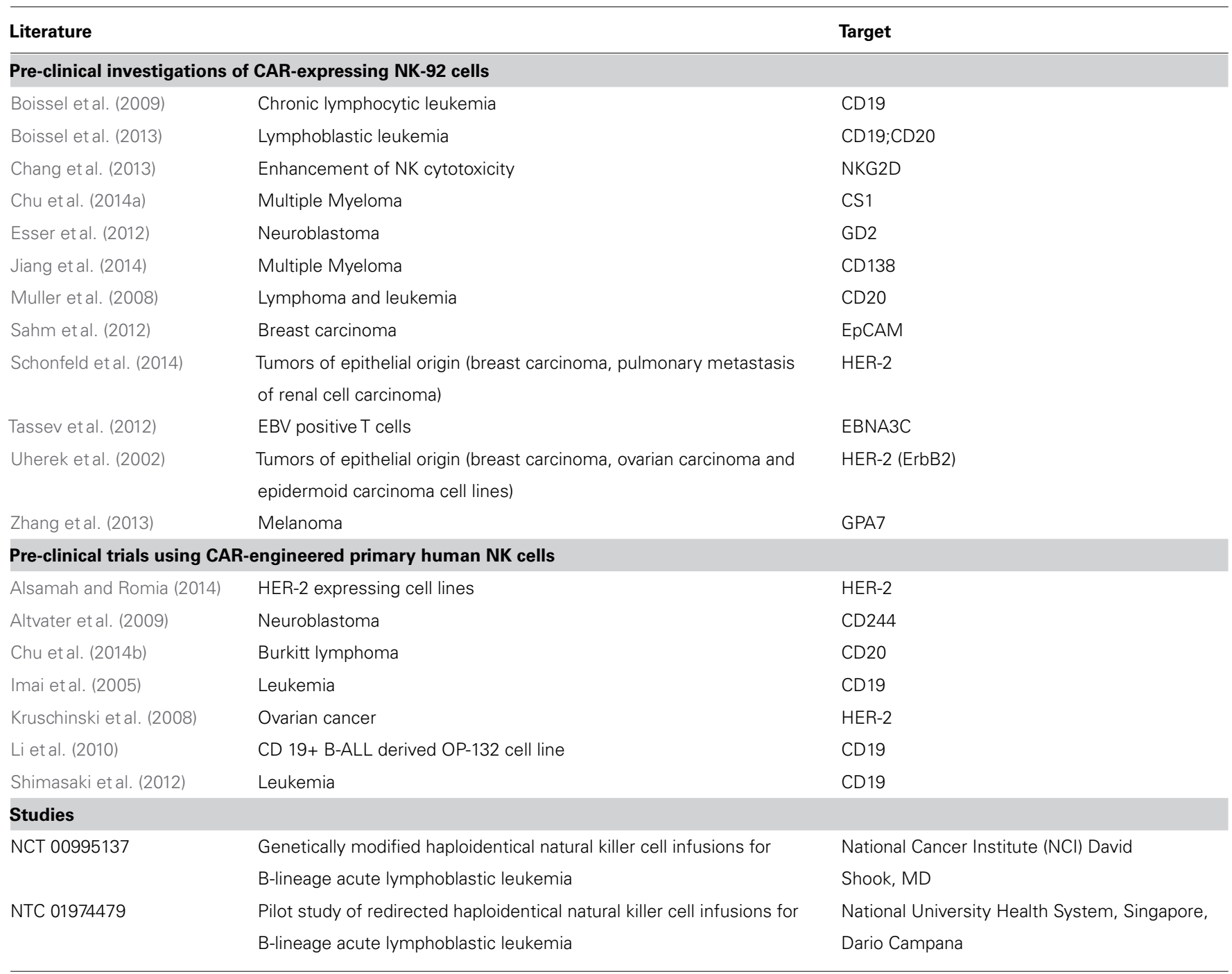

efficacy for lentiviral vectors of $8-16 \%$ for $\mathrm{PB}$ and $12-73 \%$ for cord blood NK cells. Clinically relevant levels of mRNA transfection were obtained with the NK-92 cell line (Boissel et al., 2009). Likewise, Shimasaki et al. (2012). showed highly efficient expression of anti-CD19 chimeric receptors in either freshly purified (median, 40.3\%) or expanded NK cells (median, 61.3\%) after electroporation of the corresponding mRNA. During transduction of the NK cell, the CAR encoding vector is semi-randomly and stably incorporated into the host cell genome. This ensures longlasting CAR expression, but may also lead to severe side effects, such as insertional mutagenesis and - in case of antigen healthy tissues - also persisting off-tumor/on-target activity. Numerous clinical studies have been performed with gamma-retro- and lentiviral vectors targeting hematopoietic stem and progenitor cells. While these approaches have clearly demonstrated efficacy, especially in inherited immunodeficiency disorders, leukemias due to insertional mutagenesis have been observed in a number of studies using gamma-retroviral vectors for the treatment of $\mathrm{X}$ linked severe combined immunodeficiency (Hacein-Bey-Abina et al., 2008; Howe etal., 2008), chronic granulomatous disease (Stein et al., 2010), or the Wiskott-Aldrich syndrome (Braun et al., 2014). Improvements in vector architecture including the design of so-called SIN (self-inactivating) vectors have allowed second generation trials, which so far have shown a more favorable biosafety spectrum with no leukemia documented up to now (Aiuti et al., 2013; Biffi etal., 2013; Hacein-Bey-Abina et al., 2014). Nevertheless, clonal dominance, i.e., the strong prevalence of a few specific clones dominating hematopoiesis, has also been observed with second generation SIN vectors (Cavazzana-Calvo et al., 2010), arguing for careful vector design and/or additional inclusion of suicide switches even in these vectors.

In this respect, numerous clinical trials using LTR (long terminal repeat)-driven gamma-retroviral vectors for transduction of $\mathrm{T}$ cells have failed to show severe adverse events related to insertional mutagenesis reviewed in (Suerth et al., 2012) underlining the more favorable biosafety pattern of retroviral applications in mature lymphoid cells, such as T cells. Although these results are likely transferable to NK cells, a systematic biosafety analysis 
in NK cells with respect to vector architecture remains to be accomplished.

\section{SUICIDE SYSTEMS}

Different safety concerns are associated with CAR-engineered effector cells, which include induction of (acute) GvHD as well as on-target/off-tumor effects, tumor lysis syndrome and cytotoxicity to normal tissues due to limited selectivity of the chosen target antigen (Ferrara et al., 2009; Stauss and Morris, 2013; Maus et al., 2014). To date, these observations are mainly restricted to CAR-expressing T cells, but are discussed for CAR-engineered NK cells as well, especially for immature NK cells.

Suicide gene therapy was first introduced in the context of human SCT performed in the 1990s using the herpes simplex thymidine kinase (HSV-TK)/Ganciclovir (GCV) suicide system (Bonini et al., 1997). Although its safety and efficacy was demonstrated, the HSV-TK system is severely limited by only being effective in proliferating cells. Due to its viral origin, HSV-TK is also immunogenic and can therefore cause the rejection of modified cells by the immune response of the host, although it has led to effective abrogation of GvHD in all clinical trials (Bonini et al., 2007). To overcome the limitations of the HSV-TK system, various alternative suicide gene systems have been developed. Previously we could demonstrate the B cell molecule CD20 as an effective suicide marker for genetically modified T cells (Vogler et al., 2010). CD20 expression on the cell surface allows elimination of the cells upon administration of rituximab. In contrast to HSV-TK, CD20 as a suicide gene may not be immunogenic due to its human origin, and elimination by rituximab is not affected by the cells' proliferation status. Nevertheless, bio-distribution of the monoclonal antibody may be sub-optimal, and normal B cells are also depleted. Different apoptotic pathways have been employed as suicide systems, including the death receptor Fas and caspase 9 (CASP9; Fan et al., 1999; Di Stasi et al., 2011). Beside very low risk for immunogenicity, these suicide genes share the advantages of non-cell cycle dependency, full clinical compatibility and optimal bio-distribution, as CIDs are small molecules exquisitely designed for suicide purposes (Lipowska-Bhalla et al., 2012). A summary of the different suicide systems was published recently by Jones (Jones et al., 2014).

None of the aforementioned suicide systems has been intensively tested in NK cells. To date, suicide genes are primarily discussed in the context of long-living genetically modified effector cells. In contrast, mature allogeneic CAR-engineered NK cells are expected to induce anti-cancer effects and disappear after a few days. Therefore, the necessity of a suicide switch might not be given (Klingemann, 2014). However, in the context of more immature CAR expressing NK cells, suicide switches might be beneficial considering that UCB-derived NK cells or immature NK cells such as polyfunctional $\mathrm{CD} 56{ }^{\mathrm{dim}} \mathrm{KIR}^{+} \mathrm{CD} 62 \mathrm{~L}^{+}$cells have a lifespan up to months. Worth mentioning would also the finding, that IL15/4$1 \mathrm{BBL}$ activated NK cells could contribute to an acute GvHD caused

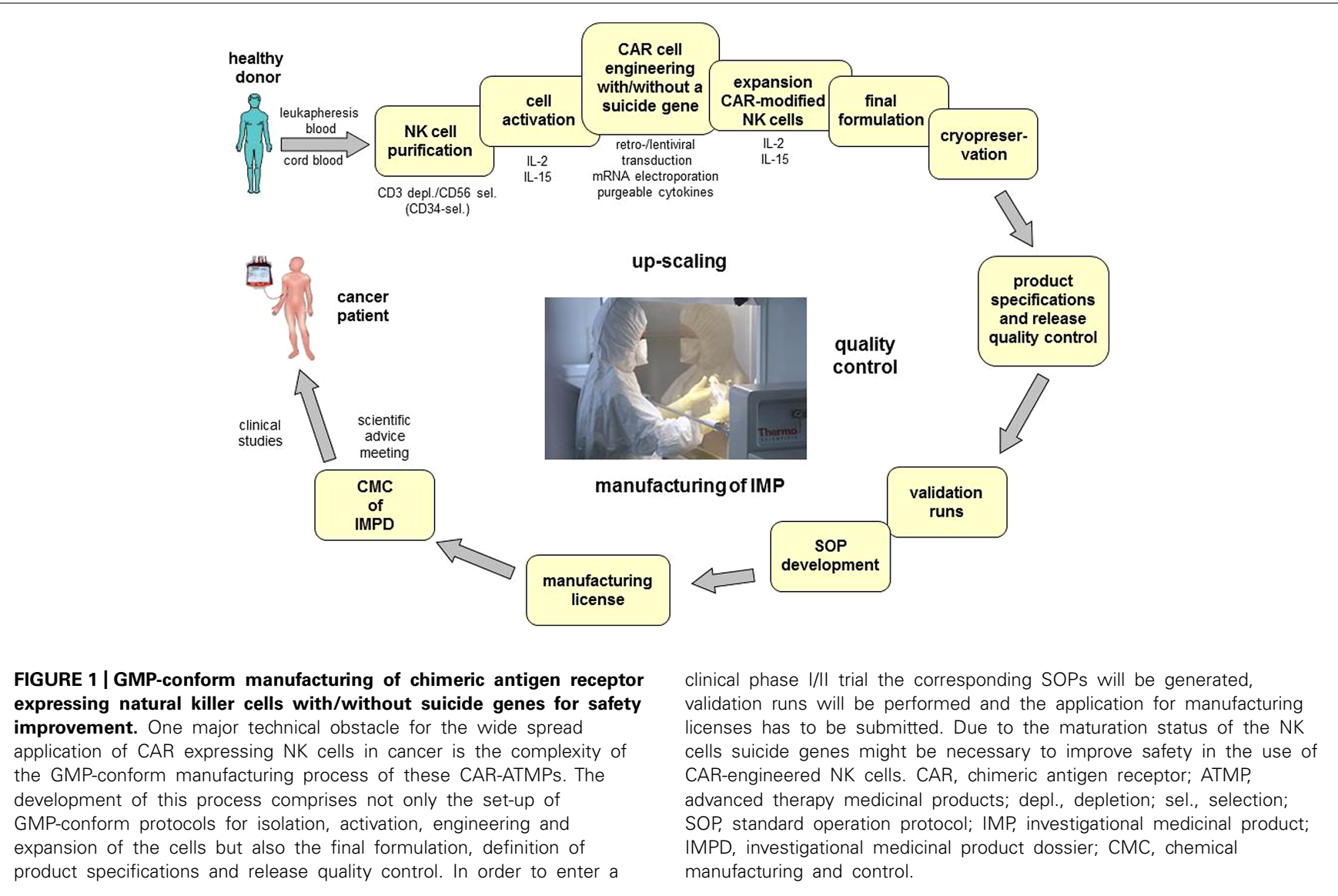


by inflammation or other factors up-regulating activating ligand expression on non-malignant tissues (Shah et al., 2014).

\section{ENGINEERED NK CELLS: FROM PRECLINICAL STUDIES TO CLINIC APPLICATION}

When compared to CAR T cells, experience with CAR-engineered NK cells is still limited. In contrast to a large number of clinical studies using CAR T cells for the treatment of various cancers, only two clinical studies employing CAR-expressing NK cells have been approved by the regulatory authorities and are open for patient acquisition. The longest open study is the pediatric study at St. Jude Children's Research Hospital using haploidentical NK cells modified with anti-CD19 CARs for the treatment of B-lineage ALL (ClinicalTrials.gov. NCT00995137). In this study, the donor-derived NK cells are expanded by co-culture with the irradiated K562 cell line expressing membrane bound IL-15 and 41BB ligand (K562-mb15-41BBL). Another study for pediatric and adult patients with refractory ALL is the recently approved study at the National University Hospital in Singapore (ClinicalTrials.gov. NCT01974479). In this study, haploidentical NK cells will be activated by incubation with IL-2 and transduced with the same construct as employed in the St. Jude trial (Shimasaki and Campana, 2013). A number of scientific questions and regulatory hurdles have to be adressed before NK CAR cellular therapy can be extended to larger patient cohorts in phase III studies, such as manufacturing issues. Although powerful methods for isolation, expansion, and transduction have been described, the preparation of the cells is still cumbersome and currently restricted to highly specialized laboratories.

\section{MANUFACTURING OF REDIRECTED NK CELLS AND REGULATORY ISSUES IN EUROPE}

According to their biological and pharmacological complexity CAR/suicide gene expressing NK cells will be classified as advanced therapy medicinal products (ATMP) in Europe and regulated either centralized or under the hospital exemption by the member states [Regulation (EC) No 1394/2007, Directive 2001/83/EC, and Regulation (EC) No 726/2004]. Although the primary therapeutic effect remains NK cell-specific the significant alteration of targeting by introduction of CAR will result in a gene therapy medicinal product (GTMP), whereas lifespan control by engineered suicidality only would result in a somatic cell therapy medicinal product (CTMP) [EMA/CAT/600280/2010 Rev.1, 20 June 2014].

For successful clinical translation of gene modified NK cells, the preclinical and clinical development (Figure 1) will have to focus on the transduction efficacy, as well as on the safety and efficacy of the CAR and/ or the suicide constructs introduced. Therefore quality aspects related to CTMP and GTMP as defined in guidelines [CPMP/BWP/3088/99; EMEA/CHMP/410869/2006; Ph. Eur. 0784: Ph. Eur. 5.14] will apply to the identity, potency, and activity including the conditional suicidality, purity, and safety of vectors and genetically modified product. The establishment of correspondingly adequate in-process and quality controls as well as of process target values and product specifications will have to take into account the variability of the primary effector cell as the starting material (Schule et al., 2010).

\section{OUTLOOK}

To date suicide gene-modified T cells and CAR expressing T cells have successfully entered clinical trials. For future clinical applications, a combination of both modifications might lead to an improved safety strategy. In contrast to gene-modified $\mathrm{T}$ cells, experiments with modified primary human NK cells are mainly restricted to the pre-clinical setting with promising results. Importantly, the first two clinical studies using CAR-expressing NK cells have started very recently. Due to the limited lifespan of mature $\mathrm{CD}_{56}{ }^{\mathrm{dim}} \mathrm{KIR}^{+} \mathrm{NKG} 2 \mathrm{~A}^{-} \mathrm{CD}^{+} 2 \mathrm{~L}^{-} \mathrm{NK}$ cells, suicide genes might not be necessary, but this could be different for more immature $\mathrm{CD} 56{ }^{\mathrm{dim}} \mathrm{KIR}^{+} \mathrm{CD} 62 \mathrm{~L}^{+} \mathrm{NK}$ cells derived from cord blood or iPS cells. While theoretical risk-benefit considerations, only argue for the incorporation of suicide switches in the context of CAR-modified and/ or more immature NK cells, careful preclinical investigations are needed to provide a final answer in the future.

\section{ACKNOWLEDGMENTS}

This project was supported by the Wilhelm Sander-Stiftung für Krebsforschung and the Integrated Research and Treatment Center Transplantation (IFB-Tx) funded by the German Federal Ministry of Education and Research (reference number: 01EO0802).

\section{REFERENCES}

Aiuti, A., Biasco, L., Scaramuzza, S., Ferrua, F., Cicalese, M. P., Baricordi, C., et al. (2013). Lentiviral hematopoietic stem cell gene therapy in patients with Wiskott-Aldrich syndrome. Science 341, 1233151. doi: 10.1126/science.1233151

Alsamah, W., and Romia, Y. (2014). Modification of natural killer cells to target tumors. Int. J. Pharm. Clin. Res. 6, 97-100.

Altvater, B., Landmeier, S., Pscherer, S., Temme, J., Schweer, K., Kailayangiri, S., et al. (2009). 2B4 (CD244) signaling by recombinant antigen-specific chimeric receptors costimulates natural killer cell activation to leukemia and neuroblastoma cells. Clin. Cancer Res. 15, 4857-4866. doi: 10.1158/1078-0432.CCR-08-2810

Battula, V. L., Shi, Y., Evans, K. W., Wang, R. Y., Spaeth, E. L., Jacamo, R. O., et al. (2012). Ganglioside GD2 identifies breast cancer stem cells and promotes tumorigenesis. J. Clin. Invest. 122, 2066-2078. doi: 10.1172/JCI59735

Biffi, A., Montini, E., Lorioli, L., Cesani, M., Fumagalli, F., Plati, T., et al. (2013). Lentiviral hematopoietic stem cell gene therapy benefits metachromatic leukodystrophy. Science 341, 1233158. doi: 10.1126/science.1233158

Boissel, L., Betancur-Boissel, M., Lu, W., Krause, D. S., Van Etten, R. A., Wels, W. S., et al. (2013). Retargeting NK-92 cells by means of CD19- and CD20-specific chimeric antigen receptors compares favorably with antibody-dependent cellular cytotoxicity. Oncoimmunology 2, e26527. doi: 10.4161/onci.26527

Boissel, L., Betancur, M., Wels, W. S., Tuncer, H., and Klingemann, H. (2009). Transfection with mRNA for CD19 specific chimeric antigen receptor restores NK cell mediated killing of CLL cells. Leuk. Res. 33, 1255-1259. doi: 10.1016/j.leukres.2008.11.024

Bonini, C., Bondanza, A., Perna, S. K., Kaneko, S., Traversari, C., Ciceri, F., et al. (2007). The suicide gene therapy challenge: how to improve a successful gene therapy approach. Mol. Ther. 15, 1248-1252. doi: 10.1038/sj.mt.6300190

Bonini, C., Ferrari, G., Verzeletti, S., Servida, P., Zappone, E., Ruggieri, L., et al. (1997). HSV-TK gene transfer into donor lymphocytes for control of allogeneic graft-versus-leukemia. Science 276, 1719-1724. doi: 10.1126/science.276.5319.1719

Braun, C. J., Boztug, K., Paruzynski, A., Witzel, M., Schwarzer, A., Rothe, M., et al. (2014). Gene therapy for Wiskott-Aldrich syndrome-long-term efficacy and genotoxicity. Sci Trans. Med. 6, 227ra233. doi: 10.1126/scitranslmed.3007280

Brehm, C., Huenecke, S., Esser, R., Kloess, S., Quaiser, A., Betz, S., et al. (2014). Interleukin-2-stimulated natural killer cells are less susceptible to mycophenolate mofetil than non-activated NK cells: possible consequences for immunotherapy. Cancer Immunol. Immunother. 63, 821-833. doi: 10.1007/s00262-0141556-5

Brehm, C., Huenecke, S., Quaiser, A., Esser, R., Bremm, M., Kloess, S., et al. (2011). IL-2 stimulated but not unstimulated NK cells induce selective disappearance 
of peripheral blood cells: concomitant results to a phase I/II study. PLoS ONE 6:e27351. doi: 10.1371/journal.pone.0027351

Brentjens, R., Yeh, R., Bernal, Y., Riviere, I., and Sadelain, M. (2010). Treatment of chronic lymphocytic leukemia with genetically targeted autologous $\mathrm{T}$ cells: case report of an unforeseen adverse event in a phase I clinical trial. Mol. Ther. 18, 666-668. doi: 10.1038/mt.2010.31

Cavazzana-Calvo, M., Payen, E., Negre, O., Wang, G., Hehir, K., Fusil, F., et al. (2010). Transfusion independence and HMGA2 activation after gene therapy of human beta-thalassaemia. Nature 467, 318-322. doi: 10.1038/nature09328

Cheng, M., Zhang, J., Jiang, W., Chen, Y., and Tian, Z. (2012). Natural killer cell lines in tumor immunotherapy. Front. Med. 6:56. doi: 10.1007/s11684-012-0177-7

Chang, Y. H., Connolly, J., Shimasaki, N., Mimura, K., Kono, K., and Campana, D. (2013). A chimeric receptor with NKG2D specificity enhances natural killer cell activation and killing of tumor cells. Cancer Res. 73, 1777-1786. doi: 10.1158/0008-5472.CAN-12-3558

Chouaib, S., Pittari, G., Nanbakhsh, A., El Ayoubi, H., Amsellem, S. Bourhis, J. H., et al. (2014). Improving the outcome of leukemia by natural killer cell-based immunotherapeutic strategies. Front. Immunol. 5:95. doi: 10.3389/fimmu.2014.00095

Chu, J., Deng, Y., Benson, D. M., He, S., Hughes, T., Zhang, J., et al. (2014a). CS1-specific chimeric antigen receptor (CAR)-engineered natural killer cells enhance in vitro and in vivo antitumor activity against human multiple myeloma. Leukemia 28, 917-927. doi: 10.1038/leu.2013.279

Chu, Y., Yahr, A., Ayello, J., van de Ven, C., Barth, M., Czuczman M., et al. (2014b) Anti-CD20 chimeric antigen receptor (CAR) modified expanded natural killer (NK) cells significantly mediate rituximab sensitive and resistant burkitt lymphoma (BL) regression and improve survival in human BL xenografted NSG mice. Cytotherapy 16:4. doi: 10.1016/j.jcyt.2014.01.064

Corrigan-Curay, J., Kiem, H. P., Baltimore, D., O'reilly, M., Brentjens, R. J., Cooper, L., et al. (2014). T-cell immunotherapy: looking forward. Mol. Ther. 22, 1564 1574. doi: $10.1038 / \mathrm{mt} .2014 .148$

Di Stasi, A., Tey, S. K., Dotti, G., Fujita, Y., Kennedy-Nasser, A., Martinez, C., et al. (2011). Inducible apoptosis as a safety switch for adoptive cell therapy. N. Engl. J. Med. 365, 1673-1683. doi: 10.1056/NEJMoa1106152

Esser, R., Muller, T., Stefes, D., Kloess, S., Seidel, D., Gillies, S. D., et al. (2012). NK cells engineered to express a GD2 -specific antigen receptor display built-in ADCC-like activity against tumour cells of neuroectodermal origin. J. Cell Mol Med. 16, 569-581. doi: 10.1111/j.1582-4934.2011.01343.x

Fan, L., Freeman, K. W., Khan, T., Pham, E., and Spencer, D. M. (1999). Improved artificial death switches based on caspases and FADD. Hum. Gene Ther. 10, 2273 2285. doi: 10.1089/10430349950016924

Ferrara, J. L., Levine, J. E., Reddy, P., and Holler, E. (2009). Graft-versus-host disease. Lancet 373, 1550-1561. doi: 10.1016/S0140-6736(09)60237-3

Grupp, S. A., Kalos, M., Barrett, D., Aplenc, R., Porter, D. L., Rheingold, S. R., et al. (2013). Chimeric antigen receptor-modified $\mathrm{T}$ cells for acute lymphoid leukemia. N. Engl. J. Med. 368, 1509-1518. doi: 10.1056/NEJMoa1215134

Hacein-Bey-Abina, S., Garrigue, A., Wang, G. P., Soulier, J., Lim, A., Morillon, E., et al. (2008). Insertional oncogenesis in 4 patients after retrovirus-mediated gene therapy of SCID-X1. J. Clin. Invest. 118, 3132-3142. doi: 10.1172/JCI35700

Hacein-Bey-Abina, S., Pai, S. Y., Gaspar, H. B., Armant, M., Berry, C. C., Blanche, S., et al. (2014). A modified gamma-retrovirus vector for X-linked severe combined immunodeficiency. N. Engl. J. Med. 371, 1407-1417. doi 10.1056/NEJMoa1404588

Holdenrieder, S., Eichhorn, P., Beuers, U., Samtleben, W., Stieber, P., Nagel, D., et al (2007). Soluble NKG2D ligands in hepatic autoimmune diseases and in benign diseases involved in marker metabolism. Anticancer. Res. 27, 2041-2045.

Howe, S. J., Mansour, M. R., Schwarzwaelder, K., Bartholomae, C., Hubank, M., Kempski, H., et al. (2008). Insertional mutagenesis combined with acquired somatic mutations causes leukemogenesis following gene therapy of SCID-X1 patients. J. Clin. Invest. 118, 3143-3150. doi: 10.1172/JCI35798

Huenecke, S., Zimmermann, S. Y., Kloess, S., Esser, R., Brinkmann, A., Tramsen, L., et al. (2010). IL-2-driven regulation of NK cell receptors with regard to the distribution of CD16+ and CD16- subpopulations and in vivo influence after haploidentical NK cell infusion. J. Immunother. 33, 200-210. doi: 10.1097/CJI.0b013e3181bb46f7

Imai, C., Iwamoto, S., and Campana, D. (2005). Genetic modification of primary natural killer cells overcomes inhibitory signals and induces specific killing of leukemic cells. Blood 106, 376-383. doi: 10.1182/blood-2004$12-4797$
Irving, B. A., Chan, A. C., and Weiss, A. (1993). Functional characterization of a signal transducing motif present in the T cell antigen receptor zeta chain. J. Exp. Med. 177, 1093-1103. doi: 10.1084/jem.177.4.1093

Iyengar, R., Handgretinger, R., Babarin-Dorner, A., Leimig, T., Otto, M., Geiger, T. L., etal. (2003). Purification of human natural killer cells using a clinical-scale immunomagnetic method. Cytotherapy 5, 479-484. doi: $10.1080 / 14653240310003558$

Jiang, H., Zhang, W., Shang, P., Zhang, H., Fu, W., Ye, F., et al. (2014). Transfection of chimeric anti-CD138 gene enhances natural killer cell activation and killing of multiple myeloma cells. Mol. Oncol. 8, 297-310. doi: 10.1016/j.molonc.2013.12.001

Jones, B. S., Lamb, L. S., Goldman, F., and Di Stasi, A. (2014). Improving the safety of cell therapy products by suicide gene transfer. Front. Pharmacol. 5:254. doi: 10.3389/fphar.2014.00254

Kenderian, S. S., Ruella, M., Gill, S., and Kalos, M. (2014). Chimeric antigen receptor T-cell therapy to target hematologic malignancies. Cancer Res. 74, 6383-6389. doi: 10.1158/0008-5472.CAN-14-1530

Klingemann, H. (2014). Are natural killer cells superior CAR drivers? Oncoimmunology 3, e28147. doi: 10.4161/onci.28147

Kloess, S., Huenecke, S., Piechulek, D., Esser, R., Koch, J., Brehm, C., et al. (2010) IL-2-activated haploidentical NK cells restore NKG2D-mediated NK-cell cytotoxicity in neuroblastoma patients by scavenging of plasma MICA. Eur. J. Immunol. 40, 3255-3267. doi: 10.1002/eji.201040568

Kochenderfer, J. N., Dudley, M. E., Carpenter, R. O., Kassim, S. H., Rose, J. J., Telford, W. G., et al. (2013). Donor-derived CD19-targeted T cells cause regression of malignancy persisting after allogeneic hematopoietic stem cell transplantation. Blood 122, 4129-4139. doi: 10.1182/blood-2013-08-519413

Kochenderfer, J. N., Dudley, M. E., Feldman, S. A., Wilson, W. H., Spaner, D. E., Maric, I., et al. (2012). B-cell depletion and remissions of malignancy along with cytokine-associated toxicity in a clinical trial of anti-CD19 chimeric-antigenreceptor-transduced T cells. Blood 119, 2709-2720. doi: 10.1182/blood-2011-10384388

Koehl, U., Brehm, C., Huenecke, S., Zimmermann, S. Y., Kloess, S., Bremm, M., et al. (2013). Clinical grade purification and expansion of NK cell products for an optimized manufacturing protocol. Front. Oncol. 3:118. doi: $10.3389 /$ fonc. 2013.00118

Koehl, U., Esser, R., Zimmermann, S., Tonn, T., Kotchetkov, R., Bartling, T., et al. (2005). Ex vivo expansion of highly purified NK cells for immunotherapy after haploidentical stem cell transplantation in children. Klin. Padiatr. 217, 345-350. doi: $10.1055 / \mathrm{s}-2005-872520$

Koehl, U., Sorensen, J., Esser, R., Zimmermann, S., Gruttner, H. P., Tonn, T., et al. (2004). IL-2 activated NK cell immunotherapy of three children after haploidentical stem cell transplantation. Blood Cells Mol. Dis. 33, 261-266. doi: 10.1016/j.bcmd.2004.08.013

Kornbluth, J., Spear, B., Raab, S. S., and Wilson, D. B. (1985). Evidence for the role of class I and class II HLA antigens in the lytic function of a cloned line of human natural killer cells. J. Immunol. 134, 728-735.

Kruschinski, A., Moosmann, A., Poschke, I., Norell, H., Chmielewski, M., Seliger, B., et al. (2008). Engineering antigen-specific primary human NK cells against HER-2 positive carcinomas. Proc. Natl. Acad. Sci. U.S.A. 105, 17481-17486. doi: 10.1073/pnas.0804788105

Leuci, V., Mesiano, G., Gammaitoni, L., Aglietta, M., and Sangiolo, D. (2014). Genetically redirected T lymphocytes for adoptive immunotherapy of solid tumors. Curr. Gene Ther. 14, 52-62. doi: 10.2174/1566523213666131223 130353

Leung, S. O., Gao, K., Wang, G. Y., Cheung, B. K., Lee, K. Y., Zhao, Q., et al. (2014). Surrogate target cells expressing surface anti-idiotype antibody for the clinical evaluation of an internalizing CD22-specific antibody. MAbs 7, 66-76. doi: 10.4161/19420862.2014.985519

Leung, W. (2011). Use of NK cell activity in cure by transplant. Br. J. Haematol. 155, 14-29. doi: 10.1111/j.1365-2141.2011.08823.x

Li, L., Liu, L. N., Feller, S., Allen, C., Shivakumar, R., Fratantoni, J., et al. (2010). Expression of chimeric antigen receptors in natural killer cells with a regulatory-compliant non-viral method. Cancer Gene Ther. 17, 147-154. doi: $10.1038 /$ cgt.2009.61

Lipowska-Bhalla, G., Gilham, D. E., Hawkins, R. E., and Rothwell, D. G. (2012). Targeted immunotherapy of cancer with CAR T cells: achievements and challenges. Cancer Immunol. Immunother. 61, 953-962. doi: 10.1007/s00262-0121254-0 
Luetke-Eversloh, M., Killig, M., and Romagnani, C. (2013). Signatures of human NK cell development and terminal differentiation. Front. Immunol. 4:499. doi: 10.3389/fimmu.2013.00499

Maude, S. L., Frey, N., Shaw, P. A., Aplenc, R., Barrett, D. M., Bunin, N. J., et al. (2014). Chimeric antigen receptor T cells for sustained remissions in leukemia. N. Engl. J. Med. 371, 1507-1517. doi: 10.1056/NEJMoa1407222

Maus, M. V., Grupp, S. A., Porter, D. L., and June, C. H. (2014). Antibody-modified T cells: CARs take the front seat for hematologic malignancies. Blood 123, 2625 2635. doi: 10.1182/blood-2013-11-492231

Miller, J. S., Soignier, Y., Panoskaltsis-Mortari, A., Mcnearney, S. A., Yun, G. H., Fautsch, S. K., et al. (2005). Successful adoptive transfer and in vivo expansion of human haploidentical NK cells in patients with cancer. Blood 105, 3051-3057. doi: 10.1182/blood-2004-07-2974

Morgan, R. A., Yang, J. C., Kitano, M., Dudley, M. E., Laurencot, C., and Rosenberg, S. A. (2010). Case report of a serious adverse event following the administration of $\mathrm{T}$ cells transduced with a chimeric antigen receptor recognizing ERBB2. Mol. Ther. 18, 843-851. doi: 10.1038/mt.2010.24

Muller, T., Uherek, C., Maki, G., Chow, K. U., Schimpf, A., Klingemann, H. G., et al. (2008). Expression of a CD20-specific chimeric antigen receptor enhances cytotoxic activity of NK cells and overcomes NK-resistance of lymphoma and leukemia cells. Cancer Immunol. Immunother. 57, 411-423. doi: 10.1007/s00262007-0383-3

Ni, Z., Knorr, D. A., Bendzick, L., Allred, J., and Kaufman, D. S. (2014). Expression of chimeric receptor CD4zeta by natural killer cells derived from human pluripotent stem cells improves in vitro activity but does not enhance suppression of HIV infection in vivo. Stem Cells 32, 1021-1031. doi: 10.1002/stem.1611

Park, T. S., Rosenberg, S. A., and Morgan, R. A. (2011). Treating cancer with genetically engineered $\mathrm{T}$ cells. Trends Biotechnol. 29, 550-557. doi 10.1016/j.tibtech.2011.04.009

Porter, D. L., Levine, B. L., Kalos, M., Bagg, A., and June, C. H. (2011). Chimeric antigen receptor-modified T cells in chronic lymphoid leukemia. N. Engl. J. Med. 365, 725-733. doi: 10.1056/NEJMoa1103849

Raffaghello, L., Prigione, I., Airoldi, I., Camoriano, M., Levreri, I., Gambini, C., et al. (2004). Downregulation and/or release of NKG2D ligands as immune evasion strategy of human neuroblastoma. Neoplasia 6, 558-568. doi: 10.1593/ neo.04316

Sadelain, M., Brentjens, R., and Riviere, I. (2013). The basic principles of chimeric antigen receptor design. Cancer Discov. 3, 388-398. doi: 10.1158/2159-8290.CD12-0548

Sahm, C., Schonfeld, K., and Wels, W. S. (2012). Expression of IL-15 in NK cells results in rapid enrichment and selective cytotoxicity of gene-modified effectors that carry a tumor-specific antigen receptor. Cancer Immunol. Immunother. 61, 1451-1461. doi: 10.1007/s00262-012-1212-x

Schonfeld, K., Sahm, C., Zhang, C., Naundorf, S., Brendel, C., Odendahl, M., et al. (2014). Selective inhibition of tumor growth by clonal NK cells expressing an ErbB2/HER2-specific chimeric antigen receptor. Mol. Ther. doi: 10.1038/mt.2014.219 [Epub ahead of print].

Schule, S., Renner, M., Longhurst, S., and Narayanan, G. (2010). Regulatory requirements for clinical trial and marketing authorisation application for gene therapy medicinal products. Bundesgesundheitsblat Gesundheitsforschung Gesundheitsschutz 53, 30-37. doi: 10.1007/s00103-0090988-0

Shah, N. N., Baird, K., Delbrook, C. P., Fleisher, T. A., Kohler, M. E., Rampertaap, S., et al. (2014). Acute GVHD in patients receiving IL-15/4-1BBL activated NK cells following $\mathrm{T}$ cell depleted stem cell transplantation. Blood doi: 10.1182/blood2014-07-592881 [Epub ahead of print].

Shimasaki, N., and Campana, D. (2013). Natural killer cell reprogramming with chimeric immune receptors. Methods Mol. Biol. 969, 203-220. doi: 10.1007/9781-62703-260-5_13

Shimasaki, N., Fujisaki, H., Cho, D., Masselli, M., Lockey, T., Eldridge, P., etal. (2012). A clinically adaptable method to enhance the cytotoxicity of natural killer cells against B-cell malignancies. Cytotherapy 14, 830-840. doi: 10.3109/14653249.2012.671519

Spanholtz, J., Preijers, F., Tordoir, M., Trilsbeek, C., Paardekooper, J., De Witte, T., et al. (2011). Clinical-grade generation of active NK cells from cord blood hematopoietic progenitor cells for immunotherapy using a closedsystem culture process. PLOS ONE 6:e20740. doi: 10.1371/journal.pone. 0020740
Stauss, H. J., and Morris, E. C. (2013). Immunotherapy with gene-modified T cells: limiting side effects provides new challenges. Gene Ther. 20, 1029-1032. doi: 10.1038/gt.2013.34

Stein, S., Ott, M. G., Schultze-Strasser, S., Jauch, A., Burwinkel, B., Kinner, A., et al. (2010). Genomic instability and myelodysplasia with monosomy 7 consequent to EVI1 activation after gene therapy for chronic granulomatous disease. Nat. Med. 16, 198-204. doi: 10.1038/nm.2088

Stern, M., Passweg, J. R., Meyer-Monard, S., Esser, R., Tonn, T., Soerensen, J., etal. (2013). Pre-emptive immunotherapy with purified natural killer cells after haploidentical SCT: a prospective phase II study in two centers. Bone Marrow Transplant. 48, 433-438. doi: 10.1038/bmt. 2012.162

Suerth, J. D., Schambach, A., and Baum, C. (2012). Genetic modification of lymphocytes by retrovirus-based vectors. Curr. Opin. Immunol. 24, 598-608. doi: 10.1016/j.coi.2012.08.007

Sutlu, T., Stellan, B., Gilljam, M., Quezada, H. C., Nahi, H., Gahrton, G., et al. (2010). Clinical-grade, large-scale, feeder-free expansion of highly active human natural killer cells for adoptive immunotherapy using an automated bioreactor. Cytotherapy 12, 1044-1055. doi: 10.3109/14653249.2010. 504770

Tassev, D. V., Cheng, M., and Cheung, N. K. (2012). Retargeting NK92 cells using an HLA-A2-restricted, EBNA3C-specific chimeric antigen receptor. Cancer Gene Ther. 19, 84-100. doi: 10.1038/cgt.2011.66

Tonn, T., Schwabe, D., Klingemann, H. G., Becker, S., Esser, R., Koehl, U., et al. (2013). Treatment of patients with advanced cancer with the natural killer cell line NK-92. Cytotherapy 15, 1563-1570. doi: 10.1016/j.jcyt.2013. 06.017

Uherek, C., Tonn, T., Uherek, B., Becker, S., Schnierle, B., Klingemann, H. G., et al. (2002). Retargeting of natural killer-cell cytolytic activity to ErbB2-expressing cancer cells results in efficient and selective tumor cell destruction. Blood 100, 1265-1273.

Velardi, A. (2012). Natural killer cell alloreactivity 10 years later. Curr. Opin. Hematol. 19, 421-426. doi: 10.1097/MOH.0b013e3283590395

Vogler, I., Newrzela, S., Hartmann, S., Schneider, N., Von Laer, D., Koehl, U., et al. (2010). An improved bicistronic CD20/tCD34 vector for efficient purification and in vivo depletion of gene-modified T cells for adoptive immunotherapy. Mol. Ther. 18, 1330-1338. doi: 10.1038/mt.2010.83

Woll, P. S., Grzywacz, B., Tian, X., Marcus, R. K., Knorr, D. A., Verneris, M. R., etal. (2009). Human embryonic stem cells differentiate into a homogeneous population of natural killer cells with potent in vivo antitumor activity. Blood 113, 6094-6101. doi: 10.1182/blood-2008-06165225

Yagita, M., Huang, C. L., Umehara, H., Matsuo, Y., Tabata, R., Miyake, M., et al. (2000). A novel natural killer cell line (KHYG-1) from a patient with aggressive natural killer cell leukemia carrying a p53 point mutation. Leukemia 14, 922-930. doi: 10.1038/sj.leu.2401769

Zhang, G., Liu, R., Zhu, X., Wang, L., Ma, J., Han, H., et al. (2013). Retargeting NK92 for anti-melanoma activity by a TCR-like single-domain antibody. Immunol. Cell Biol. 91, 615-624. doi: 10.1038/icb.2013.45

Conflict of Interest Statement: The authors declare that the research was conducted in the absence of any commercial or financial relationships that could be construed as a potential conflict of interest.

Received: 05 December 2014; paper pending published: 07 January 2015; accepted: 24 January 2015; published online: 12 February 2015.

Citation: Glienke W, Esser R, Priesner C, Suerth JD, Schambach A, Wels WS, Grez M, Kloess S, Arseniev L and Koehl $U$ (2015) Advantages and applications of CARexpressing natural killer cells. Front. Pharmacol. 6:21. doi: 10.3389/fphar.2015.00021 This article was submitted to Experimental Pharmacology and Drug Discovery, a section of the journal Frontiers in Pharmacology.

Copyright () 2015 Glienke, Esser, Priesner, Suerth, Schambach, Wels, Grez, Kloess, Arseniev and Koehl. This is an open-access article distributed under the terms of the Creative Commons Attribution License (CC BY). The use, distribution or reproduction in other forums is permitted, provided the original author(s) or licensor are credited and that the original publication in this journal is cited, in accordance with accepted academic practice. No use, distribution or reproduction is permitted which does not comply with these terms. 